\title{
URBAN SPRAWL - THE LEGAL CONTEXT AND TERRITORIAL PRACTICES IN ROMANIA
}

\author{
Bogdan Suditu* \\ Department of Geography, Bucharest University $\mathcal{E}$ \\ General Direction of Territorial Development, Ministry of Regional Development and Tourism, Bucharest, Romania
}

\begin{abstract}
Urban sprawl limitations are objectives of public policy of all European Community documents referring to urban and territorial planning. Nowadays clear and stable boundaries between the areas of towns built during the communist period are replaced by their fragmentation and perpetual transformation. Presently, the strategies and instruments of urban sprawl control depend largely on the legal tools and the efficiency of the cooperation between local public administrations in urban and metropolitan areas.
\end{abstract}

Key words: Legislation, Urban sprawl, Public authorities, Residential areas, Urban development.

Article Info: Manuscript Received: February 29, 2012; Revised: March 25, 2012; Accepted: May 15, 2012; Online: May $29,2012$.

\section{The urban sprawl within the European context}

The issue of urban sprawl and associated motilities is a current priority one on the European Union and national institutions 'agenda. In the European policy documents and in the literature of specialty, urban sprawl refers to the development outside the cities of residential pavilions, among other activities, which cause strong environmental, functional and landscape transformations.

The term "urban sprawl" indicates a negative connotation of how urban development is achieved, reflecting the meaning of the English word "sprawl" (uncontrolled urban development) or of the French "etalement urbain" (with the same meaning), and the opposite of "urban spread "(controlled urban development). Urban sprawl occurs when the conversion rate and the use of land for urban purposes exceeds the rate of population growth in a particular area and in a certain period of time.

Urban sprawl is now regarded as one of the major common issues urban Europe is facing today. Nowadays, even where there is little or no pressure from the population, various factors still lead to

\footnotetext{
* Correspondence address:

Address: University of Bucharest, Faculty of Geography, 1, Nicolae

Balcescu Avenue, 010041, Bucharest, Romania

Telephone: 004 0749.196.889
}

urban sprawl. They come from the desire to promote new lifestyles in periurban environments.

The multiplications of the forms of mobility, the quality of the transport systems, the land prices, the individual preferences for living, demographic trends, traditions and cultural constraints, the current attractiveness of urban areas, all have an important role in terms of how an urban area is developing. Motilities' current trends, targeting new low density urban areas, lead to increased land consumption. Space consumed by a person in European cities has more than doubled in the last 50 years. In the past 20 years built surface areas in many countries in Western and Eastern Europe increased by $20 \%$, while population grew by only 6\% (European Environment Agency, 2006).

Mobility and accessibility are key factors in the territorial cohesion of Europe, being essential elements in the definition of the quality of life of periurban communities. But the quality of life in the new periurban developed residential areas in the past decades depends on the coherence of spatial planning, municipal infrastructure provision and functional relationships between residential areas and those destined to work (in cities and periurban areas). But strategies and instruments of urban sprawl control depend largely on the efficiency of the cooperation between local public administrations in urban and metropolitan areas.

Email:b_suditu@yahoo.fr 


\section{Urban developement in Romania - the urban planning tools and actors}

Transformations in the last two decades are witnesses of this process of development of the construction, with residential, industrial or services destinations, in areas surrounding cities, under its pressure and influence. Clear and stable boundaries between the areas of towns built during the communist period are replaced by their fragmentation and perpetual transformation nowadays. One builds a lot, building perimeters are increasingly extending, being more and more fragmented. But the most obvious phenomenon remains multiplication of constructions and the expanding of the perimeters built and where one can build.

Urban sprawl is the result of the search for alternatives to housing and urban environment. By constructive or mobility initiatives, those involved have sought a way of living as close to their needs as possible, but also to nature. But through their actions, in the absence of public coordination (transport infrastructure, utility networks, public transport, urban planning), they contributed to the transformation of rural areas, to the destruction of natural features and landscapes, as well as to the excessive urbanization of areas classified as rural by chaotic or highly dense buildings or which do not meet the specificity of the place, part of which being located in isolated or fragmented groups outside the villages.

In Romania, in local public administration, the main tool for planning with operational character is the general urban plan. Urban plans have a specific regulatory nature and establish rules that apply directly to the settlements and parts of them up to the parcel level. The general urban plan is the document that stipulates urban functions and rules as well as boundaries on which one can build - a limit to the built area. In conformity with the stipulations of the territorial and urban planning law, a limit to the built area includes the "total areas built and furnished of the settlements that compose the basic administrative territorial unit, defined by the general urban plan approved and in which the execution of construction and facilities may be authorized" (Territorial and Urban Planning Law $\mathrm{n}^{\circ}$ 350/2001). Usually the limit to the built area is made up of several corps and its surface does not correspond to the surface occupied by buildings, being always more extensive.

Perimeter limits, in which one can build, are initially established by General Urban Plan (PUG) approved by each local public authority. This simultaneously regulatory and operating instrument has the validity of a decade. In the absence of formal prohibitions in the law of urban planning, by 2011, the limits of the built area evolved - in the sense of extension of the perimeters in which to build - by promoting zonal urban planning documentation (PUZ) that land one cannot build upon located in "not built "was introduced in "built area".

The initiative could belong to both local authorities as well to any land owner, as for this operation there is no requirement of the existence of a minimum or maximum surface. Regardless of the initiator, the documentation of change in land status followed clear procedures of technical approval procedures and was taken by the local council. In this context, between 1990 and 2011 numerous areas of land have become lands where one could build upon, even if did not have the minimum municipal infrastructure and access and parcel sizes were specific to farmlands. Thus, by fragments and isolated, the area to build extended permanently in accordance with the legislation on urbanism and housing, local authorities assuming - by approving of the documentation of the extension to built area their public utilities equipment.

But local budgets being limited, the share of the newly developed perimeters equipment that benefited from public utilities is reduced. The gated communities, even those isolated outside the cities, have provided buildings and infrastructure, not all of them being connected to the infrastructure.

In order to limit the phenomenon of fragmentation of the built perimeters of settlements and the proliferation of isolated dwellings, in 2011 at the initiative of the Government, territorial and urban planning law was changed. Thus, although the built extensions are still possible, by changing the planning law may be introduced in built areas lands with at least 5000 square meters - when the future destination is related to service activities and at least one hectare when the future function is a residential one. This regulation aims to limit the fragmentation of lands that can be built upon and a more coherent harmonization of new developers with the existing settlement.

\section{Built-up area - element of the budget allocations setup}

Clearly, extending the surfaces on which one can build is proportional to the dynamic of the need of housing or economic activities. Expanding urban perimeter translates an economic dynamics and imposes costs to equip these perimeters. In this respect, in the context of territorial development disparities in Romania, in order to support local authorities in the less developed areas, the formula for balancing local budgets through contributions 


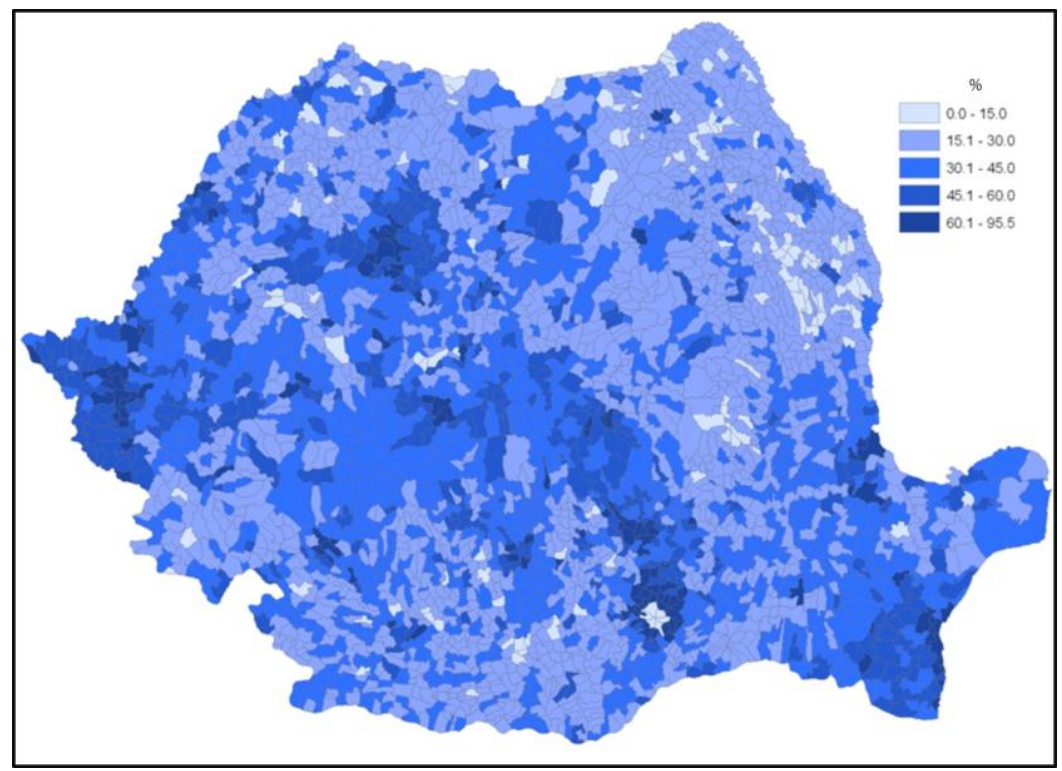

Figure. 1. Percentage of the local incame in the total local budget

from the state budget, a coefficient of built-up area was introduced.

In 1996 the new law on local public finances changed the allocation of state budget amounts to the local budgets. Thus, in order to balance local budgets of territorial-administrative units, certain amounts deducted from the state income are approved, according to the following criteria: population, the built-up area of the administrativeterritorial unit and the financial capacity of the administrative-territorial unit. In the analysis made by local departments of public finances, after verification of financial capacity of municipalities, the other two criteria contribute in determining budget allocations as follows: the share of the population of the administrative units of $75 \%$, the share of built area of administrative units in proportion of $25 \%$.

Self-revenues map analysis of the share in the total budgets obtained by territorial administrative units confirms the existence of territorial inequalities. Thus, broad geographical areas where the share of their own revenues represents the majority point out: capital - Bucharest and its area of influence, the urban corridor of Bucharest - Ploiesti - Brasov, southern Transylvania (Brasov, Sibiu, Alba IuliaSebes), the area of influence of the municipalities Cluj-Napoca, Targu Mures and Bistrita, west of the country (Timisoara and Timis, Arad), and Constanta and its area of influence. On the other hand, half of the towns and cities in Romania manage to provide only $30 \%$ their operating budgets from their own income. The lowest values correspond to geographical areas located in the eastern and southwestern Romania, and isolated in southern Banat (Caras-Severin), Transylvania (Apuseni Mountains). (Figure 1).
On the background of the modification of the legal framework regarding local public authorities, and under the housing pressure of the last decade, the extension of the in-built area acquired a double logic: a functional one - in terms of the urban regulation for new areas to build on, a budgetary one - the in-built area entering the formula of the budgetary allocations to the respective locality.

\section{Dynamic disparities of the built surfaces}

In the context described above, in the past few years, at the initiative of local authorities, by the regional urban plans covering the introduction of land in the built areas or when reviewing the general urban plans, the built surface of settlements was extended. The analysis expansion of the built area correlated with the dynamic of housing and population shows no direct relationship between them in all places that have requested the extension.

The analysis of the map of the ratio of the built-up area expansion during 1990-2011 shows, on one hand the general trend of increase in these areas, and on the other hand, obvious similarities in certain counties in practices of expansion (Neamt Nasaud, Salaj, Caras-Severin, Ilfov, Bucharest). The absence of expansion or the negative values recorded are explained by the deficiencies of the statistical records between the two reference years, during which most localities that record such values being administratively divided by the separation of some settlements and the establishment of new communes around them. Generally, statistical information show that over $0.15 \%$ of the localities, the built surface multiplied by over $100 \%$. (Figure 2 ) 


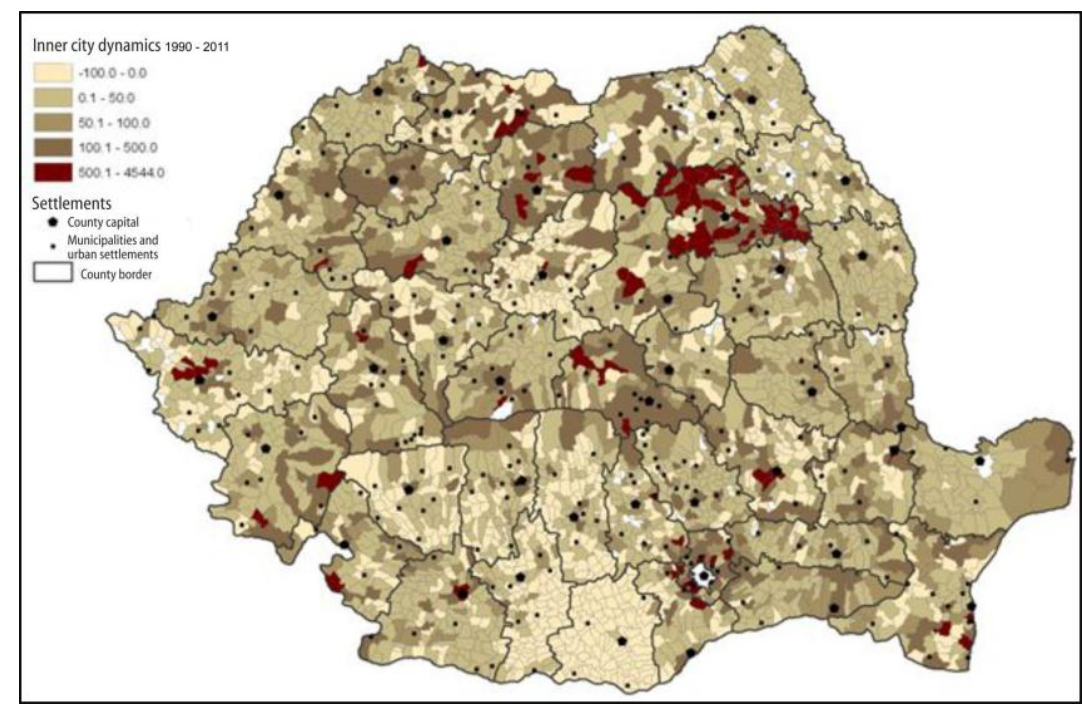

Figure 2. Built land areas dynamics 1990-2011

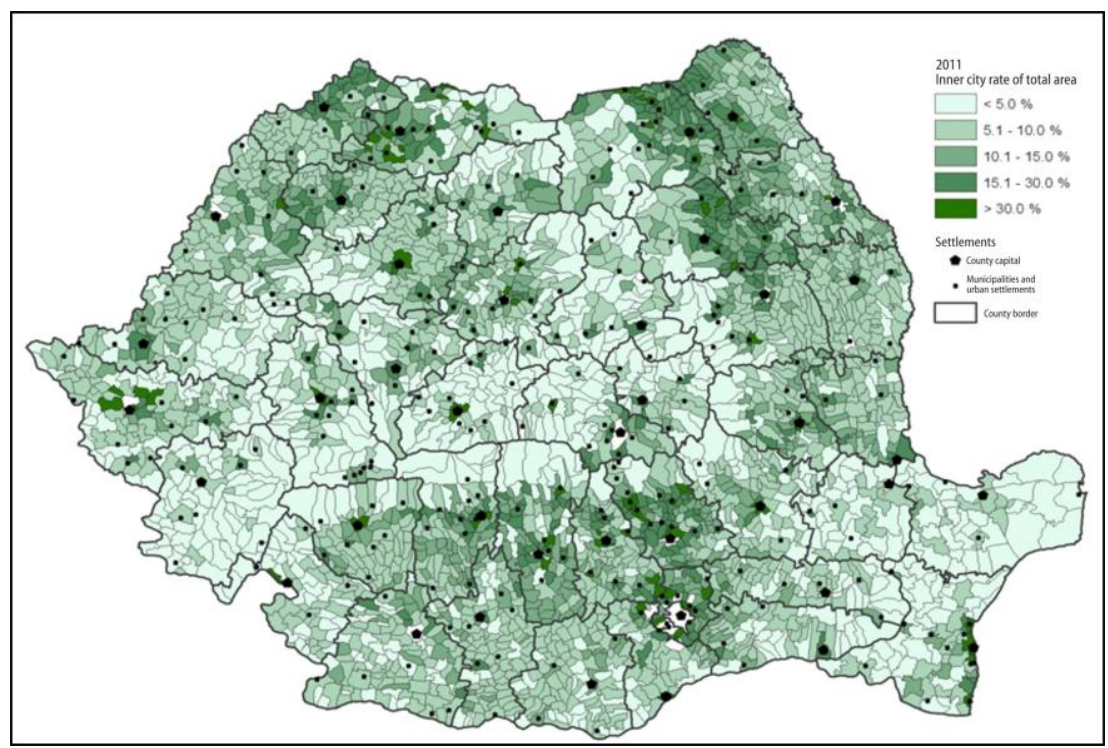

Figure 3 Percentage of built land areas in total surface (2011)

Strong dynamics of these surfaces in the area of the capital - Bucharest are recorded, urban areas and urban corridors, but also in mountain or hilly areas near major cities due to the construction of numerous secondary residences in these areas. and dynamic The correlation between built-in expansion housing stock changes explain the high values of transformations in the urban areas and partially on the eastern and southeastern areas of Romania.

Regarding the share of the built-up areas in the total area of the village, the values are also differentiated and translate the same estate and budgetary aspects already mentioned. Thus, reduced share of the in-built areas, less than $5 \%$, characterizes the less populated areas: mountain villages, the Baragan area (Braila County and eastern of the county of Ialomița), the Danube plain (west of Constanta county) and the Danube Delta. The highest values recorded in urban areas (Bucharest and the county of Ilfov, the Prahova Valley and Brasov, Constanta, Timisoara, Cluj-Napoca, Oradea, Pitesti), the upper valley of Siret (east Suceava and Neamt county, west Iasi and Botosani county), and most villages and cities in counties of Salaj and Maramures. (Figure 3)

\section{The future of urban sprawl in the context of present local practices}

Nowadays, even if Romania - as part of the European agreements on reducing energy consumption and limiting consumption of fertile farmland - must take all measures to limit urban sprawl. Since lands to built upon are not necessarily used for constructions, theoretically the extension of the limits of the in-built areas affects only the way in which local budgets are 
supplied. Practically, however, the extension of the in- built areas requires from local authorities - under the legislation in use regarding urban planning and constructions - the acceptance of the authorization for building itself, isolated from the corpus of the settlement and assuming the costs necessary to ensure the infrastructure in urbanized perimeters.

Ensuring the urban consistency in new residential developments is limited by the absence of other legal and operational tools that can merge land and draw urban networks. Also a significant problem in ensuring the consistency of urban development through expansion is linked by the set up of new forms of participation in financial contributions necessary for infrastructure and utilities.

\section{References}

European Environment Agency 2006, 'Urban sprawl in Europe. The ignored challenge', in EEA Report, no.1o www.eea.europa.eu

Federal Ministry of Transport, Building and Urban Development 2007, Territorial Agenda of the European Union. Towards a More Competitive and Sustainable Europe of Diverse Regions, Agreed on the occasion of the Informal Ministerial Meeting on Urban Development and Territorial Cohesion, Leipzig

Federal Ministry of Transport, Building and Urban Development 2007, Leipzig Charter on Sustainable European Cities, Agreed on the occasion of the Informal Ministerial Meeting on Urban Development and Territorial Cohesion, Leipzig

Suditu B., 2010, Urban Sprawl Characteristics and Typologies in Romania, in HUMAN GEOGRAPHIES Journal of Studies and Research in Human Geography (2010) 4.2, 79-87 